\title{
The Unbearable Heaviness of Being: Pain and Suffering in Anorexia
}

\author{
Lissy Canellopoulos ${ }^{*}$
} National and Kapodistrian University of Athens, Faculty of Psychology, Panepistimiopolis, 15784 Ilissia, Athens,
Greece

\begin{abstract}
In anorexia which classically shows the difficulty in adolescence to link bodily transformations and sexuality, psychic suffering is undeniable and is embodied in the body while taking into account contemporary social data. Building on some elements of the psychoanalysis of a young anorexic girl, the article attempts to break through the wall of pain and get to perceive that in an order that is no longer governed by the paternal instance, which allows the representation, the subject can no longer support a phallusized image and the body is reduced to its reality. This results in a particularly painful female transmission in the clinic of anorexia, in which the contemporary world is not innocent. Pain is not the goal for the anorexic; it shows a willingness to feel the existence of the body. She seeks this nothing through which she attempts to capture the rift in the Other. But to achieve this nothing she must feel the pain of its absence. Pain is thus a claimed effect. The article ends with a reflection on the therapeutic work with the anorexic subject, which would be to allow the dis-completeness of the discourse concerning it, to reintroduce a relationship to its own image marked with a lack and offer the conditions of its own enunciation.
\end{abstract}

Keywords: Acting-out, anorexia, feminine, pain, real father.

\section{INTRODUCTION}

"It's this eccentricity of desire in relation to any satisfaction which allows us to understand [...] its deep affinity with pain. This means that what ultimately desire confines in is simply and purely [...] this pain of existence" [1].

If I had to illustrate anorexia it would be through the open mouth of the head of Medusa by Caravaggio, this famous painting which dramatizes a moment of emergence of something experienced in the body. The image evokes the painting of Munch, The scream, or also St. Teresa by Bernini in ecstasy: an open mouth on nothing, suggestive of pain, anxiety, even horror, as well as a mysterious jouissance.

If the body returns the human being to its vital needs, its psyche inscribes it as a being of desire in relation to the other. What is inscribed on the body refers thus to the desire understood as a call to human communication. This inscription on the body could be located in the interval between speech and silence, in this voiceless space, in this place boundary of the symbolic, close to the real, near the opacity of the subject, at the edge of the rift of any discourse.

Based on Lacan's witticism: "clinic is the real" that is to say the unbearable as such, and to illuminate something about anorexia as an inscription into the body of the pain -the unbearable- of being, I will question the painful journey and the suffering of a patient put into words during an analytic treatment, a suffering which revolves around a lost body, torn from its subjectivity, stranger to itself, unheimlich.

*Address correspondence to this author at the National and Kapodistrian University of Athens, Faculty of Psychology, Panepistimiopolis, 15784 Ilissia, Athens, Greece; Tel: 0030 6945992979; Fax: 00302107277534; E-mail: 1canel@psych.uoa.gr

\section{PRELIMINARY ON PAIN AND ANOREXIA}

"But finally, what turns into somatic pain? Carefully we will answer: something that could and should have spawned a psychic pain" [2].

Distinguish pain from suffering is essential. We could formulate this distinction as follows: pain refers to something somatic, physical, mainly neurophysiologic, while suffering indicates a much more general phenomenon of psychic nature. Let's remind that in many texts, L'Esquisse [3], Inhibition, Symptom and Anxiety [4], or Beyond the Pleasure Principle [5], Freud repeats exactly the same model with which he explains somatic pain. Freud will separate somatic from psychic pain at the end of his book Inhibition, Symptom and Anxiety [4]. Or rather it would be more correct to say that he assimilates psychic to somatic pain [6]. Thus we could argue that "there really is no difference between physical and psychic pain, because pain is a mixed phenomenon" [6] p. 32 .

Anorexia has the peculiarity of associating physical pain to psychic pain. It illustrates, in the specificity of the relationship it reveals between body and psyche, the complexity of the issue of experience of pain and its place in the psychic economy of the subject. It offers the very example of pain experienced as a jouissance. But how to decipher anorexia, this inflicted pain, increasingly common in the so-called developed countries?

It seems that anorexia has the particularity to have a history that goes beyond the proper clinical setting, with a strong social or cultural component and demonstrates the essential role of the body and its social representations. So, far from being a modern phenomenon, its amazing current progress reveals, however, that we live in a world that 
pushes towards totality, towards the individualism, the Undividualisme, the One. The anorexic wants "nothing" in a world where we want "everything." Contrary to popular belief, the anorexic is hungry, very hungry, to be invaded by a physical and psychic pain against which she constantly struggles every day. She never ceases to refrain from feeling her body, and she seeks - and finds most often - every trick to try to forget about the pain, bustling in a frantic manner: work pushed to the limits of what is feasible, excessive sport and activities. To self-inflict such a suffering is generally incomprehensible to ordinary mortals, and more often for their parents and relatives who are confused by this refusal to eat, especially since food is one of the first elements of parenting and particularly maternal.

Psychoanalytic clinic teaches us that anorexia is not an entity in itself. It is about anorexia in its classical form, when femininity is a key issue, that Lacan has said that the anorexic is not the one who does not eat anything; she is the one who eats "nothing", the "nothing". The nothing is not an absence of something, the nothing is something, Lacan said. The nothing is for Lacan an object; strange object certainly, and paradoxical, as we shall see, because it is not identifiable to the food neither. This "symptom" is certainly worrying her entourage and manifests mainly in its relation to the Other: the anorexic asks for nothing, hence the great difficulty of establishing a treatment. How, if she eats nothing, as Lacan says, can she consent to throw this nothing in the psychoanalytic discourse? Within what logic does its "symptom" come?

If someone can give us an idea of what the body discomfort can be for the being afflicted with speech, it is the anorexic pushing this discomfort, mild form of anxiety, says Lacan in his seminar X [7], to the most unbearable limit, the evocation of the corpse in her own body, real annihilation of the flesh. Throughout his teaching, Lacan's main thesis about anorexia nervosa is to say that the negation brought into play is not about the act of eating but about the object that is eaten. The very anorexic's act does not state "I do not eat" but "I eat nothing". Faced with the mother on whom it depends, what the anorexic subject does is to savor an absence, because nothing is precisely something that exists symbolically [8]. To eat nothing is then presented as the subject's attempt to point out the oral object not as a mere object of need but as a significized object, sign of the love of the Other. Faced with a cramming will inscribed in the Other as the Other asks the subject to let himself be fed [9], the anorexic tries to save her desire reminding the mother that the child is thirsty for her love and not for milk and no food can satisfy that hunger of recognition of her being. She will close the circuit of need, since she tells us that one may die of hunger, with the physical and psychic pain that this entails, so as not to die in the sense of desire, not to be lost as a subject.

But to consider the anorexic behavior only as a disorder of the oral sequent to a profound disturbance of the relation to the mother, we miss what makes the moving force of its issue rather centered on a failure of the father in his function of real father. Emphasizing her determination to give the object its symbolic status reveals that it is not only in the face- to-face of mother and child that the undercurrents of anorexia settle, but in a failure of the paternal operation to make happen as a symbolic lack the imaginary phallus first perceived in the mother. This failure (missed) of the castration operation hinders the anorexic subject's access to the deprivation rendered impossible because "no dialectic of deprivation itself can be established except about something that the subject can symbolize" [10]. Faced with the impossible deprivation ${ }^{1}$, the anorexic, in order to overcome this failing symbolization utilizes the frustration where she can imaginarily shake the lack of a real object that is food. She cheats on her knowledge about her elusive lack. This allows us to understand why a clinic that does not have the valuable tool that Lacan left us by distinguishing the three levels - imaginary, symbolic and real - of the lack of the object, could consider the mother, agent of frustration, as casting in the problem of anorexia nervosa, where as it is the imaginary father as an agent of deprivation which is revealed to be in issue at the last term.

It is on this theoretical background that I propose to explain the rather stormy unfolding of the analytic cure of an extremely decided anorexic young women that I will name Rose, who inspired me with the attack angle of this work and allowed me to reflect on what plays out in anorexic pain. When Rose comes into my office in a state of quite severe malnutrition, my eyes are automatically captured by this young skinny girl. This capturing of my glance has something automatic; it doesn't proceed from any intent. It seems to me that faced with these patients, whose body irresistibly evokes the corpse register, our look, either we are male or female, is immediately that of a worried mother. This context specifically excludes any possibility of eroticization of the look. Such a clinical point of departure could therefore lead us to approach this picture through the scopic drive as well as through the oral drive. In other words, this subjective position of mine, ignoring the sexual question, leads to bringing to the foreground the function of the look and to redesigning the place of the different partial drives, and immediately puts me on two paths of thinking: the capturing of the glance and the hide-and-seek of the sexual question. It seems to me that in this very simple identification one can find the basic elements able to illuminate something of what is involved in the anorexic pain.

\section{THE HORROR OF KNOWING}

Rose was 21 years old when she came to see me to ask for help, in deep distress. In fact, she does not know how to leave her partner, she says. It is only at the end of the session that she announces, as she had stated that she is "bulimic with activities", that she "does not eat." She will say a little later: "The reason I want to get well is to study and become functional" and thus puts on the foreground her own relationship with knowledge. There is no doubt that there, in the love of knowledge, lies her anorexic jouissance. In fact, Rose is studying art, music, dance, singing, horse riding, sailing ... but is it worth it? She does not yet know that the cost, in front of which she steps back, is the cost of

\footnotetext{
${ }^{1}$ According to J. Lacan, there are three levels of lack: frustration whose agent is the symbolic mother, is the imaginary lack of a real object. Castration whose agent is the real father, is the symbolic lack of an imaginary object. Deprivation whose agent is the imaginary father, is the real lack of a symbolic object.
} 
castration, accepting the sacrifice of her little idealized world to share the world with others. And indeed, since her "disease", she spends long periods cutting herself off of everything, stops attending her classes, lives at her own pace, repeating her days with endless jogging, and spending long exhausting hours of physical exercise. She spends her sessions describing her obstinate position to stay in her little world.

It is customary to observe the particular appetite of anorexics for studies where they often stand out as brilliant students. A bulimia for knowledge often comes in contrast with food restriction in them. But what do they do with all this accumulated knowledge? Just absolutely nothing, except may be feeding the greed of the Other. And Rose likes to show me how much she loved everything she did until her "illness", but would not touch the dishes carefully prepared by her mother. There would be in Rose something like a refusal to go through the knowledge of the Other. This horror of knowledge would appear as a "too few for me" she opposes to a desire for knowledge attributed to the Other. I suggest at least reading this reference to anorexia that Lacan introduced at the end of the lesson of the $9^{\text {th }}$ of April 1974 of the seminar Les non-dupes-errent when he says that the anorexic is "so concerned about whether she eats, that in order to discourage this knowledge [...] she would leave herself starving" and advances the idea that it is not the desire who presides the knowledge but the horror [11].

Freud had already placed the drive to know - this "pousse-à-savoir" mentioned by Jean -Pierre Deffieux [12] in his presentation of the Leonardo case - on the side of the jouissance and not of desire. It is about Leonardo da Vinci [13] that he develops a correlation between drive of knowing and drive of seeing whose fate depends on the subject's response to meeting the maternal castration. Rooted in sexual drive, this drive of knowing is the indication of the questioning of its place in the Other's desire. The question is rather to understand how libido infiltrates knowledge for Rose, rather than lead to sexuality, and in what way? I think that the oral drive comes into play in an equally important way as the scopic drive in the relation of the subject with knowledge and that this fundamental fantasy of fellatio Freud managed to rebuild concerning Leonardo da Vinci, proves well what has to be accepted regarding the incorporation of the phallus of the Other when it comes to learning. Rose hardly uses the phallic referent. Indeed, the intellectual work would require this moving in the bounding of the Symbolic and the Real, which weakens the phallic jouissance in favor of a jouissance of the Other, which is also a jouissance of the literal body of the Other, and thus of the maternal body. This body of the Other, holey, makes aspiration, this suction Rose seems to so vividly experience.

\section{ROSE'S HISTORY}

As Rose's parents work, they hire a nurse with excellent recommendations - German by chance - to take care of Rose, two months old. The first time of her analysis Rose cannot remember the details, but remembers that the nurse was harsh, excessively punitive and made the law at home. "Every hour and moment in front of the nanny was a moment of potential humiliation, as perfect as one tried to be." Rose waited in vain for a sign of love coming from her nanny, it would never come. "Anything I did, and I tried to be perfect, was for her to give me some love." The hunger for love she has known is a request addressed to the mother through the nurse. For the nurse who used to take the children for a walk with a leash, Rose said: "I had often thought about passing the police station, to go and say that this woman was beating $u s$ ". But she particularly remembered when the nurse forced her to eat her vomit, to that point she had to swallow what was imposed. It is literally about a prohibition to expel the object out of the body and the imperative to incorporate "the object being eaten" [8], the phallus of the Other, which refers us to the difficulty of separation between body and jouissance, on which we shall return. Since then, Rose has never dared to vomit again. She said she understood how much the character of the nurse was at the center of her drama "I know that the disorder is directly associated with those things. Because in the hands of this woman I felt fear and danger constantly lurking "; and her parents also become a threat equal to the nurse:" All that I was going through with the nanny was with their approval. I consider them accomplices in the whole process. [...] I wanted them to save me, to intervene."

During our first sessions Rose shared with me all the misunderstanding she had been subjected to for years from her parents: "Full communication gap. In adolescence, I felt that my parents did not understand me at all, I didn't share any thought with them, they were not interested in getting to know me ". On the other hand, Rose communicated very well with the maternal grandfather who came often to visit them. But for fear of grieving his daughter, he prevented his granddaughter to denounce the nurse to her parents. It is only when the parents discover that the nurse had hit the little brother that they dismiss her, not without her brutal reaction. Rose was then ten years old.

Throughout her whole childhood and adolescence Rose was hyperactive with singing, music, horse riding, ballet, sailing and many other activities and won prizes. But she said: "I hated my body and always tried to hide it". In fact, she always had more pounds, which was a source of teasing and remarks from her ballet teachers (she was called "donut of the gang"), her classmates and others about the "ugliness that made me hate myself, that hurt me in adolescence and childhood."

Rose had her menses at 12 years old and was horrified, "I knew what follows, another age .... And now, if I return, it would mean a symbolic change. I don't want a normal sexual life, I want the childishness. In fact I renounce my gender. I feel it's wrong, but I cannot manage it." Establishing a sexual identification turns out to be necessary, when the conflict and the inclusion of an otherness cannot be ensured and assumed. Nevertheless, we had to wait for another moment a few years later for anorexia to occur.

This moment occurred when she was 17 and moved in with one of her friends' brother. "As we did not talk with my parents, I came across just anybody". Her parents show their disagreement with this relationship. But Rose said: "I had the feeling they don't know me. How do they interfere? They didn't raise me and never listened to me". Also, "When my grandfather died I kept falling and when I saw that I was losing everything I invested on, I put in my life the first one I found in front of me", she says. A man who listens to her, 
unlike her parents, but "who likes nothing but eating, watching TV and sex". She begins eating and drinking with him and gets fatter. "I was eating because I couldn't stand the man I had next to me". Pregnant, she aborted financially helped by her brother and a friend, and returns - despite of her - to live with her companion, "so that her parents would not see her in this state".

"The only hope was her grandfather. I couldn't wait to hear the key on the door." But the beloved grandfather dies. "I really miss the love he showed me, his weakness for me, even if he didn't say anything about the nanny to my parents... Because nobody would ever go into the empty body again." Suffering from the death of her beloved grandfather causes a painful tearing sensation into the body which has to empty itself from being. She then made the decision to lose weight "enough" and stop drinking. Talking later in analysis about the death of her grandfather becomes conversely the starting point of a change she feels "It's weird how the change occurred from one day to another." Change that becomes apparent in the fact that she finds the taste of food again and begins timidly to eat, even if it is only with baby cutlery and in the company of her family. "As if I started my life from the beginning," she says.

She makes a trip to Germany - idealized country of her nurse - during the summer of her $20^{\text {th }}$ birthday, from where she remembers: "I felt like home, I'm here. No eating, no sleeping, to have the time to see everything. I was free. You did find your paradise, why should you eat? Spiritual food was enough for me. Freedom beyond everything. It fills me so much." Scopic drive and oral drive are in a close relationship here. In The Seminar, Book X, Anxiety, Lacan evokes a certain "vampiric" relationship from the baby to its mother, but what is revealed, is rather the aura of anxiety that surrounds the oral relationship to the mother [7]. It is understood that the solution to this anxiety by Rose is found in the signifier she calls " spiritual food ", a signifier that recalls that other Greek significant dear to Plato "theorein", which originally means eat, and subsequently eat through the eyes, contemplate, think. The harrowing oral jouissance becomes intellectual jouissance and strangely brightens Lacan's remark in Les non-dupes errent [11] on the anorexic "concerned to know if she eats".

\section{THE ENDLESS COUNTING}

It is on the return of this trip and after a phrase that got thunderous into her head that she stops eating "You no longer need to eat. Over there I had everything." She will impose this hunger systematically to herself. "The only thing I felt was that I wanted to lose weight, to keep losing. Every thought of mine had to do with that." And every pound lost is both pleasure and pain. "It's the tyrant that breaks out in me, the one who says he hates me, I'm a horrible person. Punishment, abuse I do to myself. There is pleasure and awe caused to me. I'm scared and at the same time there is pleasure from something that harms you directly... How did I get to the position of the abuser?"

For Rose the question is to eat as little as possible. But "possible" is too much, strictly speaking. Indeed, it is a "minus" indefinitely and without purpose: "The barrel (of losing weight) has no bottom." It is, on the balance of calories or body, about a pseudo-succession of numbers each one being an imperative signal for achieving the next one. Subjectivity is like abolished behind it, and Rose is of a very curious obedience, as if she was totally helpless in front of a parade of numbers solicited almost automatically. However, these numbers have the effect of nullifying the subjective inscription that some signifiers could produce. Always less, indefinitely, is better than to imagine a stable limit. Because not being able to stop eating is the real fear.

She actually describes a big fear of an imaginary bulimia: "I'm afraid of my feelings. As a closed door behind which there is much hubbub. The hubbub is "I'll get fat" but responds through the "nothing". Because to desire something is impossible, one must desire the nothing. Lacan makes of this nothing a figure of the object $a$. What concerns the "nothing" is very clever, because it mimics the hole that is the object $a$, it pretends to be like it.

And Rose doesn't stop being caught in the absolute control of her body through this counting. Not eating equates for her to "to regaining control." Everything is counted, calories, pounds, excretions, but also the whole of daily life, work, hours spending physically exhausting herself, sport, anything can be predicted, everything can be calculated. She says: "I want to control everything. When I get out of my programming, when things are not in order, I'm afraid I'll lose control, I'll collapse, it causes me confusion and panic. I want my body to be as I want, as I define it. I want it to act with my own algorithms." This counting seems to infiltrate her discourse as her words escape spaced out in a slow rhythm, halting and oddly steady, as if she was counting the words she delivered too. Does she try this way to make up an imaginary margin in the de-pacing of the drive, where we can still spot a trace of subjective activity?

How can Rose, too much in love with her metric count, be extracted from the linear that anorexia produces time after time and out of which she has made her body and her faith? I tried to find in the forged memory I had, the opportunity to show her how what she had sometimes said took a new sense and that a closure could be attempted.

Let's note in the fragment that we can read in Lacan's seminar ... ou pire that there is something feminine in the calculation of real numbers [14]. Let's not forget that "to not eat" comes as a link in the chain demand of love-separationtravel to the idealized country of the nurse. Rose was losing weight very quickly, as she says, and "The first time after the breakup I was having too much fun when femininity was disappearing ... What is redundant is the feminine... The hair is the only item on me that testifies that I am a woman. Now, the component which will dominate is the unnoticed ... the shadow". We shall return on the subject of femininity.

\section{THE UN-HEIM-LICH OF THE BODY, THE MIRROR AND THE DENY OF THE DIS-COMPLETENESS OF THE DISCOURSE}

But at 39 kilos for a height of $1.75 \mathrm{~m}$, Rose will say: "I see myself in the mirror like two elephants, not one". The mirror reflects to her a "too much", an excess: "A fat that is excessive..." Even though very skinny, she always finds herself too fat in the mirror and every appearance of flesh dips her in the highest anxiety. Why doesn't she feel thin, 
why doesn't she see herself thin? Why what others say on her weight has no effect?

So, I revert to my look captured by Rose's scrawny body and the approach of the question through the scopic drive. Rose seems to denounce through this nothing that she pretends to be nourished by, what is deficient in the structure of the discourse that concerns her and she demonstrates it through her body. She was searching for the foundation of her identity in the deficiency of dis-completeness of the discourse, but she is seeking it there in vain and attempts to incite it in the field of the different drives that are disentangled from their relationship to speech. "When I eat, I try so that nothing is left inside", she says in order to counteract the compulsion of the incorporation of the metaphorized "vomited" object. "That nothing is black, schwarz and mainly unerkannt, unheimlich."

It is when she released this word that she says during the next session that she is "better, happier". And she moves on: "Unheimlich" contains "Heim" home. "Not even inside me can I find a place to roost. My body is a stranger. All this Unheimlich with the body, this worrying alien that I've always felt towards my body. Now I see that nothing is in place. I am not, I'm absent again from the Unheimlich". She cannot rely on her subjective division which is the object of a denial, nor that of the other. The drives are no more vectorized by the expelled meaning trait. They are not partial experiences anymore, where the subject experiments in the different orifices of his body, the dis-completeness of the discourse of the Other. Here the drives, each one to its own count, are aiming to arouse the dis-completeness in the partial field that is its own, without the meaning frame that offers the lack of a dis-complete discourse. At the anorexic, in the oral drive, the object is reduced to nothing: "Every time that I eat nothing, I fly". In the drive of invocation, the call to the Other is reduced to the greed of the letter: "The spiritual food was enough to me". But also: "I admired the knowledge in my nanny. I believed that she knows it all... I wanted to look up to her on everything". In the anal drive, the exchanges are reported in the numbers, in the coding of weight, of losses, of the too much. In the scopic drive, Rose catches the eye.

If the anorexic catches the eye, it is that she meets a look that wants to be attentive on her and the look of the interlocutor - which is me - becomes an integral part of the symptomatic manifestation. If that is true, what does this catching of the eye consist of and what consequences are we to draw on the anorexia and the therapeutic strategy for its approach?

If the eye is caught, it's because the anorexic offers through what she gives to be seen of her own self, a space where the eyes of the other can be caught and thus, tie up her scopic drive. What does this space consist of? If the anorexic supposes that in the field of the look the other is discompleted, it's because she's searching for this discompleteness in the other and that she's searching in the scopic for the dis-completeness which she lacks in the field of speech and whose witness is her quest in the register of food.

We notice that the anorexic approaches her body through the look that is cast on some part of her body, a part that is supposed to bear traits of femininity, thighs, buttocks, belly, breasts, etc., by complaining for an excess in the form, "What is superfluous is the feminine...", while she offers to the look of the other, a body marked by a loss. The body of the anorexic is offered to the look of the other to make him notice an excess, where he is sensitive about what lacks in the body in order to affirm the carnal dimension of the sexuality. This reference that the anorexic makes for her body is divided in a double way: only the scopic drive is engaged to this quest of a point of reference and through touch, there are successively different parts of the body that are offered to the look of the other, rather than the unity of the body itself: "When I have a bite, I touch my belly that it is so bloated then, as if I was a child of Biafra". By touching her body, the anorexic is reassured about the real of a loss, which the image of ego does not seem to take into account. This dichotomy makes us suppose that the anorexic is found trapped by a reflection of herself, which is not marked by a lack, - we find again in the image, the defect in the discourse of the other - as the image of ego i (a) is theoretically in the stage of the mirror.

Actually, through the dis-completeness of the look, it's a default of the division of the discourse concerning this discompleteness that the anorexic is confronted with. And Rose narrates a memory: In the pram yet, she is found locked in the elevator with her nanny. "I was so scared that I would never manage to get out of the elevator with her. Our relationship was such. We are trapped in with one another and we will never be untrapped". Rose is confronted with a nanny-mother that does not consent with a division towards her daughter and a dis-completed discourse, thus her relationship with her image is marked. This impact is less manifested at the initial time of structuring the image of self, since Rose is not psychotic, than during the confirmation that she regularly comes to look for in the discourse of the other, especially of the nanny-mother.

If the discourse that concerns the anorexic is not marked by a lack, it becomes imperative, direct and not reversed anymore. The image that is correlated with such a discourse is not marked by a lack anymore; it becomes "all" imaginarily phallic. That means that on the basis of the structuring of a discourse and of an image that was initially marked by a lack, since the anorexic is not psychotic, a direct imperative discourse comes to be pressed. This imperative discourse imposes to the anorexic to be wedged in an expected image of her which is not structured from the speech in a non-inversion of the image. Thus, the look of the other sends her back an inversed image of self, not structured by the reference to the symbolic, not marked by the castration i $(-\varphi)$.

We discover why the anorexic does not see herself thin, in other words of what consists the gap that the anorexic proposes to the look of the other: she introduces, through the loss of flesh from the parts of her body that are offered to the look of the other, a gap with the image, that the imperative and direct discourse of that other imposes to her to accept. The structure of the symptom is thus found in between the two of them, between the gap and the real of the discomfort or the suffering of the other that she arouses. And the trait offered to the look in this way, the constitutional lack of the image and the sexual meaning of the lack, remain radically strangers for the anorexic. 


\section{A BODY WITHOUT FLESH MADE OF CORE AND AN AIR ENVELOPE}

Rose relates a dream: "My nanny was dying or had died. I've not had a chance to see her". And she comments on her dream:"I'm afraid that something might happen to her... I do not think that it is the fear that my nanny will die. It's the fear of gaining weight because I had eaten everything I forbid myself to. I do not know if it's for my nanny or if it's the punisher in my head." The ban is in the field of orality and passes through the mother-nurse.

She says: "As if I wanted to keep the childish body, or rather to find what I never had, the innocence. I like not being menstruated, not having a sexual life, curves ... I want the erotic element to be completely absent and I prefer to be a child." And during the first months of her analysis Rose says about eating baby food with baby cutlery and connects it to fairy tales or German nursery rhymes from her childhood: "That nanny I adored and adore, but who punished me so hard that I didn't have the time to live my childhood. Now, instead of waking up memories, I woke up the child in me". Rose finds refuge in childhood. It is less a rejection of the selection of gender, or a refusal of femininity, than a refusal of the gendered body as such. This is the solution offered by the anorexic: in her refusal to go through the mediation of the body, she hence breaks free from the phallic constraint that, by objectalizing her, would plunge her into the triviality of desire. Rose wants to be a spirit, that is to say a subject and not a body. She dreams of a body in which there would be nothing in, just a core and an air envelope, without feminine forms that exceed. She tries to make a body without flesh, to be in shape without filling out. Everything seems as if the anorexic aspired to erase the mark of secondary sexual characteristics. Escape from the reality of sexuality and death by an attempt to subvert the oral drive paradoxically emphasizing its purely erotic side (eating nothing).

It is in this direction that she has a second dream: she is in a dance school. An entire wall is covered with fridges filled with vegetables like in the super market. "I felt an erotic attraction to vegetables because they were without calories, exactly what I wanted." Rose cannot think of sexuality but based on the ideal model of mother-child fusion, however, devoured by the vampire concern that can be called "cannibalism." The absence of phallic mediation is only too obvious.

\section{THE SEPARATION BODY/JOUISSANCE AND THE REAL FATHER}

Rose's memory of her confinement in the elevator with the nurse completed by her dream could not announce any better the subjective position of Rose who is obliged to always repeat in the real the negativation of her flesh. I insisted above on her extreme anxiety of always finding herself too fat in the mirror, even very thin, and I tried to explain this discrepancy between the mirror and the look of the others by looking for the dis-completeness in the discourse of the Other. However, the birth of the subject is absolutely correlated with the birth of the Other by incorporating what Lacan calls the "symbolic body" in" Radiophonie ". He states: "incorporeal is the function [...].
But incorporated is the structure that does the affect [...]. Corpse stays [...] the body that inhabited the speech, that language corpsified "[15]. This incorporation process of the body of the symbolic results in a symbolic annihilation of the body and gives the body the status of corpse - English term introducing thus structure and body separation/jouissance. But it's the real father who realizes this operation, the real father as eaten, incorporated, thereby sparing the place of a vacant topic. We insist on the fact that the Other exists only as embodied symbolic and not as pure symbolic. This persistence of the anorexic to negativate her flesh results from the badly assumed separation by the subject between body and jouissance, causing the need for her to constantly separate body and jouissance.

Thus well established in its negative existence, the subject may then avoid this emptiness lending itself to symbolic identification with the real Other. Freud had already described the cannibalistic primary identification with the father before the constitution of the object and denoting the birth of the structure. The transition from "Radiophonie" [15] seems to elucidate the relationship between the drive and the question of the father allowing us a reading of the so enigmatic cannibalistic primary identification with the father, in which Freud saw the primordial form of love. From this point where the structure arises, one can identify two seemingly contradictory sides: The slope of the incorporation of the body of the symbolic and the slope of the incarnation that rather appears from the side of the necessary bonding to the body of this jouissance that has deserted it and that cannot be done, as Lacan says in seminar XX, but through the language itself [16].

This apparent contradiction between incorporation and incarnation is resolved if we consider these two aspects as two different, not temporal but logic, times of the reports of body and jouissance. With the anorexic subject, we find an enhancement of the slope of incorporation at the expense of the slope of incarnation. I suppose that the anorexic refuses incarnation - and not the body as one might be tempted to say - and that this refusal of incarnation would be a rejection of phallic jouissance. Who can doubt for even a moment that its goal is a fierce desire to negate the flesh, accompanied by a no less decided refusal of incarnation, which means of phallic jouissance?

\section{THE PERVERSION (PÈRE-VERSION) OF THE NANNY-MOTHER}

A few months after the beginning of her analysis, Rose meets her nanny after the insistence of the latter. This meeting, during which memories of a series of tortures experienced (for instance, she would put soap in her mouth so that one wouldn't hear her cry when she hit her) emerge again and something comes back, leaves her devastated.

It becomes justified to wonder where her parents were. Actually, Rose describes a mother who obeyed to the supreme judgment of the nanny concerning the attitude to follow towards the children ("She directed her completely"), and a father "perplexed... because he didn't know German and I spoke German". As for the nanny, she ignored the father completely "She ignores him. She always did that, especially to my dad" and, in her per(e)-version, she acted 
like a "phallic" mother, installing her perverse law on everyone. She appears like a mother who does not allow the father to dispossess her from the phallus (in a symbolic meaning) and who does not allow the child to encounter the maternal castration. A mother who makes the law to the father. "She doesn't allow neither deprive, nor dispossess", Lacan would say [10]. Father, mother and children were on her mercy, a fact that not even the grandfather would succeed reversing. We remind ourselves that it is not enough that the father's speech makes the law for the mother, the symbolic law of the separation, but he also has to show that he can give the mother what she desires, that is, that he really possesses the phallus and that he can make use of it.

At the following session, Rose claims that "after the last session many things have been put in order. I understood why I was thinking inside of me: I adore her (the nanny), but I hate her at the same time. She was unethical. I felt a bit like crazy, like having two selves. I was her pawn, she manipulated me... I was a human being, not something that is simply trained". And Rose goes on explicating her parents' behavior: "They had both lost their mother. Maybe because my mother had lost her own. She needed my nanny as a model. Just like she wouldn't object her mother, she behaved the same way with the nanny". Thus, father, mother and grandfather deliver her to the mercy of this woman's perversion whose jouissance entirely aspirated for Rose to be transformed into an object of jouissance. And Rose puts herself on that place of an object which is destined to bring jouissance, she swallows this infinite and united Other and she makes herself swallow and "I never manage to spit it, like the apple of Snow White".

In her passion of nothing, of the absence that lies behind the signifier, the anorexic strikes the unique object of her hate and love: the mother, the mother's body, her own self in a same motion of negativity that propels her towards a great infinite and united Other. She attempts to deprive the Other from the object that she was for him, from its affiliations, and denies every subjugation; in the illusion concerning the laws of language, she devotes to being re-generated, to take unique responsibility of her identity ("Since I was little, I wanted all by myself...", "All this attitude of autonomy and independency that I wanted to show them (parents), frightened. I was an escapist, always."), seeking not to be the positivized object, but the positivized subject of her object disappearance, inscribing a new articulation of subject and death. In some way, she contacts the infinite Other who commands the absolute sacrifice, she is dragged in a jouissance that can go till death.

\section{THE ANOREXIC ACTING-OUT}

During all this period, Rose shows her confidence to the analysis and her determination to change something. She comes regularly and looks forward to her sessions with much impatience: "Here I find myself again". She passes from moments of true analysis during which she questions the motives of her decided position of jouissance, succeeded by moments of true acting-outs concentrated on the demonstration of her alimentary "efforts". But after the famous encounter with her nanny, she is astonished to experience an "awkward grief, I can't be interested in anything" and the anorexia returns even further, punching a long period where she remains in the acting-out. She continues to come, but at the same time continues to talk to me about her sessions of endless "meals", her obsession to get thinner, her detailed preparation of the meal: "I want for my food to be so obsessively spotless and uncontaminated...I watch out on everything", her indigestions to every bite and tutti quanti. She tries, in vain as she says, to get even thinner, to take control of her body as to ensure that she is not the object of this other who aspirates her and enjoys from her: "I ask to see that it obeys, reacts (her body). I reduce the consumption, it won't do a thing. Not even inside me can I live, breathe. What's supposed to happen, will I stay entrapped in this body forever? If it obeyed, I would stop... I want to dominate it, for my presence to be felt. Cause inevitably, others will take on the ownership of my body. I feel rage...." Despite all my efforts to bring her back with an infinite patience on her work of free association, I assisted, powerless, to this massive return of anxiety in her body, sequent to the feeling of losing its mastery and becoming the land of a ravaging invasion that pushes her to the acting out. She almost managed to make me yield from my desire of analyst, as long as she brought her suicidal drives in front of the scene, since I continued of course being very worried about her.

This is what leads me to the idea that the anorexic behavior does not raise from the symptom, but from the acting-out. Hence the difficulty that we encounter to make these young girls enter the analytic discourse. Contrary to the symptom, encoded enjoyment that is content to itself, the acting-out is a demonstration, a call to the Other to interpret it [7] and signs a failure of the symbolization and an unwitting will of the subject to impose the non-swallowable dimension of the object by the signifier. The acting-out, Lacan tells us, is the object $a$ that jumps on the scene to say what it has to say and makes a mess, and the anorexic knows very well how to turn her family upside down.

\section{THE SYMPTOM AS TROPHY}

Then, after the encounter with her nurse, came a second event causing a stir in Rose's life and analysis. Timidly and with many obstacles, she made a promising friendship with a young man of whom she said: "It was something out of life, $T$, that I did not impose compulsively. He didn't care if the disorder was evident. He had a pure look into me." However, a few months later, $\mathrm{T}$ confides his doubt to her about his identity: is he gay? "All the ideal I was seeing in $T$ began to collapse, to weaken". T was for her a" Platonic promise." "I didn't want to relive the erotic", and thus a guarantee that she should not have to take action, every drive appearing as a threat for her to be "swallowed". But the avowed homosexuality of her friend reveals her that "although she did not get in the process of acting, the drive was there". And Rose added: "So long have I excluded the chapter of erotic life, how hypocritical am I. I stopped every erotic drive". Including the one that makes her eat to live. Not only does she completely stop eating for two days after the admission of $\mathrm{T}$, so that in too weak a state, she cannot leave her house, but this confession gives her also the idea that she could never take the place of her friend - who has never had a sexual life at 30 years old - and understand him, a game which she indulged passionately. She associates it to 
the unique relationship she had for two and a half years. D was the brother of her friend. After a rather drunken party, she decided to sleep at his house not being able to get home, and "wakes up in pain" from sexual intercourse. "I swallowed it. I convinced myself that I wanted it. There was no "no", there was no desire." And throughout their relationship, "I did everything he asked me for him to be satisfied."

"This man was the trophy towards my parents. My symptom is my trophy against this man. How can I save myself from this ex post court, from repetition?" Would her fault be to necessarily engage in demand, in dependence on the maternal Other and on its signifiers?

\section{SOME THOUGHTS BY WAY OF CONCLUSION}

Historical conceptions of anorexia show the permanence of a type of relation that some women have with their bodies, in which the difficulty of the representations of the body manifests itself in suffering and pain inflicted and where this relation works as a mirror of social oppression of femininity.

But beyond the oppositions which separate these historical conceptions, a point at least meets them: the deprivation that these women inflict upon themselves causes physical, sometimes major pain, that they will try to control, support, even look for, to the point as to make it one of the key issues of their control. Rose is attached to this pain of hunger she feels in her body and not only intellectually. It is not for her a question of soothing or calming it with drugs, for example. Nor is it a question of avoiding it or asking another to relieve her. On the opposite, it is a question of mastering it, making a sort of daily companion of it, a mark of distinction in relation to others, even an indication of superiority to all those who, according to her, do not know how to resist to it. The analytic experience will highlight this paradoxical attachment to the symptom (the subject does not want to give in to suffering under any pretext), its anxiety, says Lacan.

There is an essential difference between pain that brings a masochistic jouissance and this hunger where resonates the abandonment of the Other, a dereliction without plus-dejouir in the encounter with the empty Other to which a woman is particularly vulnerable. In this direction, pain plays a key role in the relation that the anorexic has with others through her own body. Even more than the physical suffering that the anorexic tries to ignore, the pain becomes the sole presence of the body. Whether it is hunger that torments her or physical fatigue that is imposed with sport, this pain testifies of willingness to feel the existence of the body through this single painful sensitivity. But, unlike other forms of pain caused, such as scarification or self-inflicted injuries, pain in the anorexic is not the goal. The anorexic is not trying to get hurt; unlike those who deliberately seek pain in cuts they inflict upon themselves. What the anorexic seeks is this nothing. It's through that nothing that she tries to take hold of this flaw in the Other, which furthermore for her as a woman, is immediately without fixity. But to achieve this nothing she must feel the pain of this absence. Pain is therefore an accepted and even claimed side effect, not justifying, as she believes, any relief.
This aspect has critical clinical and therapeutic implications. Clinically, it shows that physical pain does not always have the same value in the psychic economy of a subject, contrary to the idea now widespread that pain manifests itself as something intolerable which has to be systematically treated before any other priority. The exclusive management of pain may lead to feelings of annihilation by eliminating the only sensory perception that persists in the psychic economy and agreed to by the anorexic. As such, taking only charge of pain would enhance anorexia to make it life-threatening.

In 1971, in the seminar D'un discours qui ne serait pas $d u$ semblant, Lacan states that "a man is only defined in relation to a woman and vice versa, and that this relation includes a third term which is the phallus" [17], that is to say, the signifier of sexual pleasure as it is limited.

It seems to me that Rose shows us that the clinic of anorexia is answering this movement of culture that tends to put aside or even exclude the reference to the paternal instance, which means to the phallic instance that while posing a limit to the jouissance, authorizes its crossing to reach sexual enjoyment. In fact, to the simple question: "What do I want?" - and to this lack of response from the Other, Rose can only answer by the passion of this nothing, according to an anorexic modality, since what prevails is the imaginary axis due to the lack of a third reference, the phallus, which limits the field of representations. Subjectivity, here, would no more be articulated to a symbolic reference in the field of the real. The exclusive oral category for this clinic indicates us that the mother is the one to whom the request is addressed - the maternal Other, in a fundamentally dual relationship, without owing anything to the phallus.

Very often, the anorexic asks for nothing and especially not to the Other, hence the difficulty of treatment. She will manage all objects, including the first object, the most vital object, the oral object. She is of course caught, as we have seen, in an impulsive type of functioning. But is the demand not a demand in a pure state, so much the drive goes around the object? This is why we can speak of an object of need, and not of demand, that is to say of an object reduced to its real dimension, the imaginary and symbolic dimensions remaining therefore unknown.

What Lacan calls the phallus, what Freud calls libido, has this sexual significance therefore turning towards sexual enjoyment, as much expected as limited and restricted too. In an order which would be no longer governed by this phallic instance, by that boundary that commands the subject to the world and to language within the sexual significance, it is not anymore the signifier that turns towards jouissance, but it is the object. That is to say that in front of the nothing of the structure that we mentioned earlier, it is no longer the sexual enjoyment that will be sought but the jouissance of the object: jouissance of the nothing or jouissance of the filling of this nothing, but jouissance without limit.

The anorexia of the young girl typically reflects the difficulty of adolescence to link bodily transformations and sexuality. The phallic instance allows its representation. When this instance is lacking, a woman is not able to support 
a phallusized image: without a possible representation, the body is reduced to its reality.

Rose leads us to thinking that it would be possible that some girls are tempted to build their own femininity without going through the father. Could there not be this attempt to develop a device that allows them to organize a transmission of femininity that would, this time, be guaranteed by the mother, since it cannot be the father? An exception, at least one, under the figure of a big oral donor would thus allow the establishment of a law that would make her whole: a whole woman becoming possible with an object, a specifically feminine lack which would thus permit to establish a particular castration for women. Orality may allow the implementation of this device with the maternal omnipotence and a specifically feminine object: the nothing, in the form of oral feature of thinness. The anorexic involves this nothing, but by making a real object out of it.

To the maternal omnipotence the daughter answers by the sacrifice always with a possible refund as the equivalent to sacrifice. It is a relationship between mother and daughter, that is to say, basically dual, without third parties. The mother's speech is supported by a lost object which implies that there is something to yield to the other, but the difference is that this object can always be found. It is thanks to the Name-of-the-Father that the object is permanently lost and sexualized. In this device, otherness, that is to say, an organized by a permanently lost object location is denied for a maternal alterity where the object is lost but may be found. The anorexic subject would have the particularity to control the maternal phallic donation with this system of calculations and accounts. There is no more of an enigma in the Other, the father is more and more certain and it is her who controls the maternal donation.

I conclude with the following question: how to bring this subject to talk when it holds on with such passion to the horror of knowing, at the source it seems to me, of the special difficulty that the analyst finds in the activation of the "subject supposed to know (sujet-supposé-savoir)" in these patients? And when what is at stake and embarrasses the analyst is this enormous energy used by the anorexic subject to destitute the phallus?

Indeed, we stumble on the difficulty of handling the anorexic acting-out. It is not because, unlike the symptom which does not spontaneously call interpretation, acting-out is a call to the Other and to the start of the transfer that it is a facilitating element of the entry into analysis [7]. On the contrary, it tends to remain a wild transfer and has the greatest difficulty in finding a real address. How to tame this wild transfer? Interpretation here has little effect precisely because the acting-out is made in order to call it, but ultimately it is not the sense that matters, whatever it is, it is the rest, the unspeakable object, hence the impasse. In his intervention the analyst must rather rebuild the act of speaking of the anorexic than use the interpretation which may be denied.

We have seen that the anorexic seeks dis-completeness in all fields of drive: the oral, anal, invocatory drive, including the driving field of look. Failing to meet the discompleteness of the speech of the Other, where she attempts to inscribe her identity, the anorexic is dispersed in a partialization - disentangled from the field of speech - of different drives, and attempts to reintroduce a void in her relationship to the other.

Working with the anorexic subject would therefore be to allow the dis-completeness of discourse that concerns her, the family discourse, often the maternal discourse, in order to reintroduce a relationship with her own image marked with a lack and offer her the conditions of her own enunciation, the conditions for the constitution of her own symptom, which are only the rough outlines of the questions of her femininity.

It is the re-entanglement of the drives to the traits of speech and the re-entanglement of this speech to the hitherto evaded body which allows the issue of anorexia. This work can only be done at the cost of a prior time of testing the symbolic reliability of the interlocutor, of the implementation of the transfer. It is her structuring of a speaking being, her subjective division, which is expected to ensure the anorexic that such an addressing is possible, so that she can articulate her speech where she seeks the discompleteness of the Other.

The implementation of the transfer is difficult because it already involves, in itself, to dis-complete the mother's knowledge. If it proves to be possible, the analysis of the transfer will be an important direction in the work. This would reintroduce the third term. That is to say that it would not be about a temporal succession of a nothing and an everything, full or empty, but about introducing a synchrony: the one and the other.

\section{CONFLICT OF INTEREST}

The author confirms that this article content has no conflict of interest.

\section{ACKNOWLEDGEMENTS}

I am grateful to my analysand who trusted me and accepted to share her discomfort with me and let me suggest my thoughts.

\section{PATIENT'S CONSENT}

Declared none.

\section{REFERENCES}

[1] Lacan J. Le Séminaire, Livre V, Les formations de l'inconscient. Paris: Seuil 1998.

[2] Freud S. Métapsychologie. Paris: Gallimard 1977.

[3] Freud S. Naissance de la psychanalyse. L'Esquisse d'une psychologie scientifique. Paris: PUF 1979; pp. 309-376.

[4] Freud S. Inhibition, Symptôme, Angoisse. Paris: PUF 1975.

[5] Freud S. In: Essais de psychanalyse. Au-delà du principe de plaisir. Paris: Pbp 1981; pp. 41-117.

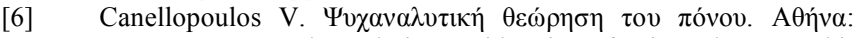
E $\pi \varepsilon ́ \kappa \varepsilon เ v \alpha$; [A psychoanalytic consideration of pain. Athens: Epekina 2012.].

[7] Lacan J. Le séminaire, Livre X, L’angoisse, Paris: Seuil 2004

[8] Lacan J. Le Séminaire, Livre IV, La relation d'objet. Paris: Seuil 1998

[9] Lacan J. Le Séminaire, Livre VIII, Le transfert. Paris: Seuil 1991.

[10] Lacan J. Le Séminaire, Livre V, Les formations de l'inconscient. Paris: Seuil 1998.

[11] Lacan J. Le séminaire, Livre XXI, Les non-dupes errent. Inédit.

[12] Deffieux J.-P. Le cas Léonard. Le séminaire théorique de la section clinique de Bordeaux. 2011. 
[13] Freud S. Un souvenir d'enfance de Léonard de Vinci. Paris: Gallimard, coll. Idées 1980.

[14] Lacan J. Le séminaire, Livre XIX, ...ou pire. Paris: Seuil 2011.

[15] Lacan J. In: Autres Ecrits. Radiophonie. Paris: Seuil 2001; 403446.
[16] Lacan J. Le Séminaire, Livre XX, Encore, Paris: Seuil 1975.

[17] Lacan J. Le Séminaire, Livre XVIII, D'un discours qui ne serait pas du semblant. Paris: Seuil 2006.

(C) Lissy Canellopoulos; Licensee Bentham Open.

This is an open access article licensed under the terms of the Creative Commons Attribution Non-Commercial License (http://creativecommons.org/licenses/by-nc/3.0/) which permits unrestricted, non-commercial use, distribution and reproduction in any medium, provided the work is properly cited. 